\title{
Drivers of Housing Demolition Decision Making and the Impact on Timber Waste Management
}

Perry Forsythe, (University of Technology, Sydney, Australia)

\begin{abstract}
The study investigates housing demolition and timber waste recovery - with the aim to identify ways of improving recovery. Using case studies the research focused on demolisher decision making, their onsite processes and the associated network of participants that influence timber recovery. From the data, a process model was developed that identifies and orders the drivers of demolition decision making. One aspect of the model identified the initiators of demolition and the waste created, including issues revolving around the demolition feedstock. Another aspect covers organisational business drivers and includes site safety, productivity, economies of scale, market value of waste and supply chain entrepreneurship. A third component deals with project specific drivers including the recurring cost versus income equation that impacts on the viability of project level decisions. The model includes a typology of the operational onsite response to the above drivers. Here, the deconstruction approach was found to provide high timber recovery mainly used where high-value timber waste was involved; the miscellaneous salvage approach provided some recovery of high and low-value timber; the crunch and dump approach provided low recovery or dumping at landfill and was used where low and no-value timber was involved. An expected increase in supply of these latter timber categories creates a significant need to increase the market value of currently low value timber groups. Designing for deconstruction is also posed as a long term strategy for this.
\end{abstract}

Keywords: Demolition, Waste management, Timber, Decision making

\section{Introduction}

The aim of this study is to investigate housing demolition with a view to identifying and improving timber waste recovery. In 1987 the Bruntland Report identified the construction industry as consuming natural resources at an unsustainable rate, causing environmental damage to the earth (World Commission on Environment and Development 1987). Since then, reducing construction and demolition (C\&D) waste has become an important part of the sustainability debate, especially the need to divert waste away from landfill (Lélé 1991; Klang et al. 2003; Duran et al. 2006). Motives for interest in this area include: lack of space for landfill (Poon et al. 2004), environmental protection (Poon 1997; Gray 2002; Smith and Bishop 2005; Xing and Hendriks 2006), reduction of carbon emissions (Krook et al. 2007), improved production efficiency (Dainty and Brooke 2004; Kartam et al. 2004; Nabil Kartam et al. 2004) and less resource depletion (Moriguchi 1999; Hendriks et al. 2000; Muller 2006)

Comprehensive waste management has been shown to provide a structured and cost effective means to reduce waste going to landfill (Schachermayer et al. 2000; Treloar et al. 2003; Rodríguez et al. 2007). Even so, C\&D waste is said to be the major component - up to $43 \%$ of the solid waste stream going to landfill in Australia (Standing Committee on Environment Communications and the Arts 2008), 38\% in Hong Kong (Tam and Tam 2006), $20 \%$ in the US (Alexander 1993; Helper 1994), 30\% in Canada (Kalin 1991) and 21\% in Brazil (Gomes et al. 2008). 
Many countries have directed legislation towards measures that minimize C\&D waste. For instance, options such as landfill taxes increase the cost of landfill which improves the comparative cost of reuse and recycling (Skumatz 1993; Morris et al. 2002; Duran, Lenihan et al. 2006; Skumatz 2008). Even so, it is often difficult to accurately foresee the efficiency and effectiveness of such regulations, especially where trying to optimise market driven methods. This is especially relevant to the management of demolition waste because it easily constitutes the largest proportion of the C\&D waste stream (Poon et al. 2001; Poon, Yu et al. 2004; Suttie 2004). Most countries have large amounts of buildings, which due to age and depreciation gradually draw towards the end of their economic utility (Moriguchi 1999). Ultimately, these redundant buildings become the feed stock for demolition and create a self perpetuating flow of waste unless redirected into reuse and recycling.

Muller (2006) explores this further by emphasising that construction and demolition flows follow a cyclic behaviour. His modelling of Dutch housing stock indicates that in the first half of the current century there will be decreasing construction and increasing demolition. He impresses that the waste from demolition is so significant that it must be seen as a key resource for ongoing materials consumption, especially given the gradual depletion of newly available resources.

Given these issues, it is pertinent to point out that many studies discuss C\&D waste as a generic construct but in viewing such studies more closely, it becomes apparent that many have an implicit orientation towards new construction projects rather than a specific focus on demolition. An exception to this includes work undertaken by the Building Research Establishment in the United Kingdom - specifically work by Hurley et al. (2001). They provide significant insight into the base principles and operational structure of the demolition industry. In many ways, this paper extends their work in providing greater structure and detail in explaining the selection of demolition processes and the impact this has on waste recovery. As such, this study aims to act at a deeper level than statistically based studies in systematically understanding the decision making of those directly involved in demolition processes.

\section{A Focus on Housing Construction and Timber Recovery}

This study takes a targeted approach to investigating demolition waste and focuses on housing demolition projects (i.e. low rise, detached and semi-detached projects). Building development of this nature makes up a significant proportion of demolition projects. For instance, town planning decisions that foster urban consolidation often require the demolition of low density suburban development to make way for higher density development. Housing projects also make for an interesting area of study given the difficulties in dealing effectively with waste because of the dis-economies of scale inherent in such small projects.

The study focuses on improving the recovery of timber. This is because timber is commonly used in low density housing construction and it is also a highly sustainable construction material - providing a naturally regenerating carbon store. Even so, the reuse and recycling of this material is not necessarily as advanced as other construction materials and improvement in this area would help support the sustainability credentials of timber as a construction material. For instance a recent study in Australia concerning extended producer responsibility (Infield 2007) indicates that the percentage of timber construction waste available for recovery is as high as $71 \%$ in Australia, $80 \%$ in the UK and $44 \%$ in the US.

In more absolute terms, the Australian Greenhouse Office (2004) estimates that approximately 2.3 million tonnes of solid wood products are placed in Australian landfills each year. Clearly, large amounts of timber could be saved from landfill and it would seem that demolition is a particularly significant sector to address. For instance in the US, timber waste from demolition is in the order of 3.5 times higher than waste from new construction

Forsythe, P (2011) 'Drivers of housing demolition decision making and the impact of timber waste management', Australasian Journal of Construction Economics and Building, 11 (1) 1-14 
(Falk 1997), in the UK it is 2 times higher (Suttie 2004), and in Australia 1.75 times higher (Infield 2007). It is therefore not surprising that the reclamation, reuse and recycling of timber waste from demolition is an area with potential for significant improvement.

Despite the scale of the problem the nature of timber waste from demolition projects (i.e. including dirt and unseparated materials) makes it hard to efficiently recover from demolition projects. Other constraints that can complicate the process further include:

- Extra time, practical difficulties and adverse attitudes to onsite separation (Falk 1997; Magin 2001; Poon, Yu et al. 2001)

- Contamination brought about by paint coatings and treated timber (Solo-Gabriele and Townsend 1999; Krook, Martensson et al. 2007)

- Building regulation and specification (Magin 2001)

- Damage to timber by machine demolition (Tanaka et al. 2004)

- Cleaning, denailing and resizing timber (Magin 2001; Tam and Tam 2006)

- Transportation and tipping fees (Mills and Showalter 2001)

- Availability of established recycling and reuse markets (McDonald and Smithers 1998)

Given the above, the current study considers the relevance of the above points and the impact they may have on diverting demolished timber away from landfill.

\section{Research Method}

A case study methodology was undertaken to address the research aims (Yin 2008). It was particularly useful in providing an integrated view of the demolition waste stream as a networked system involving different stakeholders, decision makers and processes, both on and off site. In asserting the benefits of this approach it is evident that the case study methodology has the advantage (over purely quantitative methods) of joining linked factors together into systems which is particularly useful where attempting to holistically solve problems. The case study approach makes it possible to concurrently tap into decision making and associated process variables with full context intact. Here, demolition contractors formed the basis of each case study and were used to observe how demolition took place on site and how supply chain networks formed in taking waste away from the site to reuse, recycle or dispose of. Demolishers also create networked links to other participants in the waste stream. This included specialist salvage subcontractors as well as those involved in transporting, processing, accepting and reselling waste. In each instance, indepth face-to-face interviews were undertaken with the directors or senior managers of the firms involved. Interview questions focused on obtaining data capable of mapping work processes, identifying relationships between those involved in the waste stream, and identifying impediments that affected timber waste recovery. In addition, active demolition sites and waste handling facilities were visited for each of the case studies enabling firsthand observations of how waste was received, processed, on-handled and/or sent to end user markets. Onsite discussions were conducted with those physically involved in such processes.

In total, 9 case studies were undertaken of medium to large scale demolition companies. The case studies were taken in equal proportion from the three most populated cities in Australia (Sydney, Melbourne and Brisbane). Thematic analysis was undertaken on the data (Boyatzis 1998) and this was used to inform the waste management mapping process. It focused on categorising theme frequency rather than content from word frequency. Themes were coded according to inductively derived categories. The study is considered reasonably generalisable when applied to demolition markets of similar style in terms of economic, construction and building industry characteristics. 
A key factor in the research involved modelling and mapping demolition work processes. Here, the main work of interest to the current study is Shen et al's (2004) mapping model aimed at assisting the planning of waste management procedures. The main contribution of this work is a systematised method for describing waste management processes using an activity flow chart. Lu et al. (2006) built on this by providing a more dynamic ability to simulate different waste management processes onsite and compare them in an experimental way. While both studies are insightful they tend to be oriented towards waste management in new construction rather than demolition projects. Given this, the current study utilised similar mapping concepts, but adopted them to suit demolition processes.

\section{Findings}

From the data, it was apparent that there were different drivers affecting demolition decision making (and subsequent timber recovery) and that this could be conceptualised as a process. The first stage in the process concerned initiators of demolition and waste creation. The second stage concerned organisational business drivers which determine systematic and strategic ways that demolishers respond to the waste created. The third stage involved project specific drivers which worked within the confines of the organisational strategy, but focused on site specific issues. These drivers of decision making were found to culminate in a set of operational approaches to demolition, which described what actually took place onsite. The following headings deal with each component mentioned above,

\section{Initiators of Demolition and Waste Creation}

In exploring this issue it was apparent that the existing building stock determines what will be demolished and what type of waste will be generated - hence this research adopts the term "demolition feed stock" in the context of seeing demolition as part of a production process that leads to waste recovery or waste disposal. As identified by authors such as Muller (2005) and Moriguchi (1999), demolition typically occurs because existing buildings have reached the end of their economical life. This is either because houses are dilapidated or redundant in meeting the owner's/occupier's/community's needs, or the land that the house is sited upon has a higher and better use than its current, brought about by market forces or rezoning of land use.

The two separately influence the predictability of future demolition feed stock, thus affecting the quantity and type of waste that will be generated. The research not surprisingly found that the type of waste that will occur is a function of the type of construction inherent in the demolition feedstock. Predicting the type of construction is predominantly defined by the time period in which the demolition feed stock was built and the associated construction style that was common at that time (which may vary according to region, town or even suburb). As a result, timber waste was found to be more prominent in the feedstock encountered by demolishers operating in certain areas or parts of a given city. In such cases, it was observed that demolishers developed standard modes of operation depending on which materials were more prevalent.

As the demolition feedstock evolved so too did the specific types of timber construction involved. For instance, sawn hardwood was more prominent in older stock, while sawn softwood and engineered timbers were more common in newer demolition stock. It was therefore evident that in time, there will be decreasing supply of sawn hardwoods and increasing supply of sawn softwoods and engineered timbers. As will become evident later in the paper, this trend has significant ramifications for certain drivers influencing the recovery of timber waste. 


\section{Organisational Business Drivers}

The next step in the decision making process was the way businesses responded to the previous item, at a strategic level. This involved making decisions that impacted on standardising and systematising demolition, to provide over-arching managerial and operational efficiency. Three factors pertaining to this and prominent in the data are discussed further below.

\section{Systematic Management of Safety Risk}

Demolition safety requirements were found to differ among case studies according to State based safety legislation and this was in turn found to impact significantly on the method of demolition chosen by contractors. For instance, manual demolition was more common where safety legislation was perceived as being unimposing on work methods, whilst machine based demolition was preferred where legislation was perceived as being more imposing, influenced by the way contractors interpreted their duty of care and subsequent exposure to risk, relative to legislative requirements. Some demolishers spoke of minimising exposure to manual demolition methods because of the high level of risk involved, the associated increase in project management and the increased costs in terms of insurance premiums and safety infrastructure. These organisations showed a systematic bias towards the use of excavation machinery instead of labour as a means of mitigating risk. This tends to work against timber since most recovery that aims to keep high re-use value intact, relies on manual demolition.

\section{Strategic Productivity and Economies of Scale}

Similar to the previous point, organisation wide decisions about productivity revolved around the use of machine versus labour based demolition. Clearly, machine usage had the potential for higher productivity and safety, but this was potentially offset by other factors favouring manual demolition, such as the ability to separate timber on site with a view to reselling it to offset project costs. Contractors showed preference for one or the other method depending on the extent and type of materials they intended to recover and the financial return expected from such materials.

As an adjunct to the above point, it was apparent that housing projects did not generate the same amount of waste as large commercial projects, and so the waste stream involved comparatively smaller economies of scale. As a result, demolishers tended to adopt approaches to demolition that were stylised to suit the context of systematising small project dynamics. It was also evident that the more a given material dominated the type of construction, the more it dominated decision making about the approach taken to demolition. Brick and concrete waste tended towards use of excavators, whilst in contrast, timber intensive houses tended towards manual demolition where intending to facilitate timber recovery.

Timber was but one material to be taken into account on a project and not surprisingly was often overshadowed by other higher quantity materials. Concrete and masonry often dominated and these heavyweight materials had greater impact on landfill fees because weight was often used as the basis for measuring waste quantity at landfill sites. There was subsequently an inclination during demolition to recover these heavy weight materials for recycling, whilst lighter weight materials such as timber had lower priority.

At a more specific level, it was evident that the quantity of timber waste on a typical project spanned a variety of sub-categories. The resulting lack of homogeneity among these categories further limited economies of scale. To demonstrate this point, demolishers perceived: 
- Highest quantities typically included wall, floor and roof framing.

- Intermediate quantities typically included floor, lining boards, claddings boards and floor sheeting.

- Lowest quantities typically included timber skirtings, architraves, doors, jambs, windows, decking boards, railings, and cabinetry

To demonstrate the potential for further fragmentation of the above sub-categories, it was apparent from previous discussion, that newer demolition feedstock used different timber materials compared to older feedstock. For instance sawn hardwoods were more common in older stock, whilst in the newer stock softwoods, prefabricated trusses, and engineered wood products (e.g. particleboard, plywood and MDF products) were more common. Such fragmentation and the need to strip down the advanced component like trusses did not provide economies of scale and limited development of highly systematised approaches to timber recovery.

A developing response to the above is the trend towards lumping timber waste together to try to generate economies of scale. This can only be done for homogenous use such as furnace fuel and in such instances there is a need to be able to filter out impurities and pollutants in process. While this does not provide the highest potential value from the waste, it overcomes many of the difficulties in trying to optimise individual material sub-categories.

\section{Market Value}

The extent of recovery of materials is largely dependent on the income that can be derived from selling them. This basic fact influenced the costs demolishers were prepared to incur to recover materials as opposed to sending them to landfill. Income from timber waste was often driven by both good and bad qualities - as perceived by the market. The grade, type, condition and state of the timber is important. Damage from wear and tear and from demolition reduces value, as does the existence of cuts and trenching in framework which reduces the usable section size. The need to pull timber assemblies apart from lining, cladding, frameworks and steel fitments also reduces market value. Similarly, paint coatings require extra work to bring them back to a saleable condition.

As a result, waste timber from demolition was categorised by the research in terms of "highvalue", "low-value" and "no-value". "High value" timber was typically made up of large cross section framing timbers - mainly hardwoods species or Douglas fir which has strong consumer demand for architectural features and furniture making, but is relatively hard to procure in the new timber market. "Low value" timbers typically include waste that could be easily separated onsite and transformed into the likes of reusable framing timber, bio-fuel and raw materials for particleboard production. "No-value" timber includes materials with no current re-sale potential or where too much work and expense is required to make the materials saleable. Such timber typically includes certain softwoods (including roof trusses which are difficult to reuse and recycle) and materials that are inherently difficult to recycle such as engineered timber sheet products - some with bonded laminates and others with volatile compound adhesives. The lack of saleability meant that for many of the cases studied, these materials became an expense to the demolisher by incurring landfill tipping fees and government imposed levies.

An important issue arising from the above discussion is that as the demolition feedstock evolves in the future, there is likely to be less high-value hardwood available and more lowvalue or no-value softwood and engineered timbers available. As a result, there is a pressing need to try and improve the viability of reuse or recycling these products. 


\section{Supply Chain Entrepreneurship}

Building on work by other authors (Dainty and Brooke 2004), it was found that demolishers exhibit supply chain entrepreneurship as a means of adding value to their operations. In short, they become materials traders a step beyond physically demolishing buildings. The entrepreneurship included attention to the cost and reprocessing of materials and finding the best market. A common theme was the need for various forms of organisational integration, and so the following examples of supply chain entrepreneurship were identified in the data:

- Vertically integrated supply chains - where demolishers operate their own salvage, re-processing, recycling and sales operations - including showroom and industrial wholesale settings. In such operations they often target specific materials - including timber - which are re-processed to varying extents to suit consumer demand.

- Symbiotic supply chains - where demolishers integrate effectively with specialist reuse or recycling operators. For instance the parties would agree on the value of the yet to be salvaged materials, and this would be subsequently factored into the demolisher's profit and cost structure for the project. The specialist operator may salvage targeted materials and then cart away for resale or pick up the materials direct from site after demolition. This symbiotic relationship creates a more efficient and stable supply chain in terms of not only improving the cost and efficiency of waste recovery, but the agreed logistics of onsite preparation, packaging, pick-up and eventual processing of recovered timber waste.

- Site centred supply chains -a more basic supply chain than the previous options because the demolisher sells recovered materials direct from site. Here the site acts as a temporary storage facility and shop front. It tends to occur where demolishers have no appropriate offsite storage facilities or where the materials are not worth the cost of offsite cartage, storage and selling. While little infrastructure is required this approach is often not feasible because it depends on available space and time especially where time based cost penalties are written into the contract.

Where high-value timbers are involved there are good examples of both vertically integrated and symbiotic supply chains in terms of efficiency and value creation. For no-value and lowvalue timbers high cartage costs ultimately reduces the viability of such options. This means that demolishers tend to price a project based on taking waste to landfill and so recovery is an option rather than a standard mode of operation.

\section{Project Specific Drivers}

While the above factors created an overall framework for demolition contractors to make organisation-wide business decisions, it was found that this was then processed down to decision making at project level. Relevant drivers of project decision making is observed in the data are detailed below.

\section{Recurring cost versus income equation}

The differences between competing approaches to demolition were identifiable according to four cost related sub-variables discussed below. Some of these are already defined in the extant literature including (Mills \& Showalter (1999), Pun et al. (2006), Begum et al. (2006), Treloar et al. (2003), Skumatz (2008), Morris et. al. (2002) and Duran et al. (2006). Even so, costs are reiterated and redefined here in order to elaborate on context and to provide a holistic framework for the drivers identified in the data, including: 
- Site process costs - Site costs are conceptualised to include the act of pulling the building down, separating materials, moving materials to a cartage point, preparing the materials for cartage. For timber this could include disassembling, de-nailing, strapping, loading and placing timber in bins, crates and trucks to facilitate waste recovery. Such labour intensive activities are costly compared to machine intensive site processes.

- Cartage costs - these costs are conceptualised to include all road and trucking costs involved in taking waste from the demolition site to a designated drop-off location (e.g. a transfer station, a recycling depot, a landfill site). These costs could clearly be manipulated separately to site costs. Inner city demolition projects typically make use of close proximity transfer stations, vertically integrated demolishers cart to their own recycling and reuse facilities, whilst others avoid cartage altogether by utilising symbiotic supply chain relationships.

- Government cost interventions - such costs are evident in the Sydney and Melbourne case studies in the form of landfill levies. Even so, the lightweight nature of timber means that such interventions have less cost impact on disposal compared to heavy weight materials, hence reducing the amount of encouragement for reuse and recycling options.

- Drop-off cost or income -This issue represents the project based realisation of the previous discussion on the market value waste. Here, demolishers would get paid for high-value waste, have a free drop off for low-value waste, or incur a cost for novalue waste. Income from high-value timber waste is seen as offering the most potential for encouraging improved recovery.

\section{Occasional Factors}

Unlike the above recurring factors, there was also evidence of occasional factors and though less common, these factors still clearly impacted in decision making as discussed below:

- Client Environmental Needs - Government and institutional clients were constantly cited by demolishers as requiring sustainable building practices including responsible C\&D waste management. For demolishers to be compliant they are required to submit and implement a waste management plan including details on how they intend to recover and treat materials.

- Contaminated materials - The impact of contaminated materials is not new to the literature including work by authors such as Smith and Bishop (2005), Shibata et al. (2006), and Xing and Hendriks (2006). In terms of this study, the main insights revolved around lead paint coatings, asbestos cement claddings (attached to timber framing) and certain types of treated timber. The handling of such materials require specific treatment in accordance with regulatory compliance which often entails the use of manual demolition in order to appropriately manage the segregation and removal of such materials.

\section{Operational Approaches to Demolition Onsite}

It was found useful to create a typology of the way demolishers pragmatically and systematically responded onsite to the previously discussed drivers of demolition decision making. The three identified approaches included the "Crunch and dump approach", the "Deconstructionist approach" and the "Miscellaneous salvage approach". Each was found to result in different ramifications for timber waste recovery. 


\section{The "Crunch and dump" Approach}

This approach was particularly used for houses constructed with significant brick and concrete content. It appeared to be driven by the way that these heavyweight materials represent the highest cost and quantity to offload at landfill locations - thus making these materials the primary target for recycling. As a result, timber is not regarded highly in waste recovery. Here an excavator with a bucket or grapple attachment is used to knock elements over and to scoop or grab materials. The outer brickwork is peeled outwards early in the process, Slab on ground construction means that the concrete can be dealt with last in the process, making it possible to recover these materials without significant contamination from other materials.

Unfortunately, the aforementioned drivers impact to the point that timber and other remaining materials become part of mixed waste and typically go to landfill. In practical terms, this is achieved by virtue of the excavator crawling over the waste, thus leaving mixed waste that among other things was typically rich in the form of crunched and splintered timber mulch. Timber is perceived as having insufficient market value to make recovery worthwhile except of use as bio-fuel, particleboard production and landscaping uses (where a number of these options were dependent on advanced off-site mechanical separation facilities). At the time of the study this was a seldom used option, but clearly had potential. Other features of the "Crunch and dump" approach included:

- The process avoids getting involved in many occupational health and safety risks by virtue of minimising manual labour

- Scaffolding and other costs associated with manual demolition are avoided

- The entire operation is very quick and lends itself to standardisation, systematisation and minimal project supervision

\section{The Deconstructionist Approach}

This approach makes greater use of labour to dismantle the building in an orderly way that aims to maximise timber recovery. It is generally used where timber recovery was worth more than landfill costs

It is particularly suited to houses with high hardwood content, with a high resale value. The process typically starts with an internal salvage of floor timbers, bearers and joists. Other internal hardware, fit-out, fixtures and cabinets are salvaged on a more selective basis, saved according to expected resale value. Other items such as doors, skirtings and architraves often have limited resale value unless involving large section sizes, rare timbers or are suitable for the heritage renovation market.

Following the above, roof coverings are removed followed by roof framing timbers. Again recovery is found to depend on resale value and items such as customised roof trusses typically go to landfill.

As discussed earlier, salvage specialists often came on-site for specific aspects of the work, mainly where high-value timber is involved. As the process onsite proceed, timber is manually stacked into metal crates or strapped into slings ready for easy transport offsite.

Specific features of the process include:

- There is considerable hand demolition involved and careful attention must be paid to site safety procedures. 
- Risks associated with safety may act as an impediment to using this approach. Scaffolding and similar safety infrastructure costs may be high

- This approach is considerably slower than the "Crunch and dump" approach. The extra time means that clients must be committed to a resource recovery approach otherwise the lost time may limit usage of this approach.

The economic viability of this approach is dependent on resale at stable market prices in order for demolishers not to incur unnecessary risk. Demolishers must be actively involved in supply chain entrepreneurship i.e. vertically integrated, symbiotic or in site centred supply chains.

\section{The Miscellaneous Salvage Approach to Housing Demolition}

"Miscellaneous salvage" is a combination of the "Crunch and dump" approach plus opportunistic addition of parts of the "deconstruction" approach - primarily internal and roof timber salvage and occasional removal of contaminated materials. As discussed under the "deconstruction approach", "Miscellaneous salvage" is dependent on the market value of timber, the ease of removing it from the building and the appropriate supply chains. This is often more realistic for internal timber but not cost effective for roof timber salvage unless high-value timbers were involved. It is apparent that even though some timber is recovered, much is still sent to landfill because the entire basis of this approach is opportunistically salvage of high-value timber, rather than all timber.

\section{Discussion and Development of a Process Model}

This provides a framework that merges the practical and conceptual understanding of timber waste recovery in demolition processes. Key drivers are identified and presented in the form of a model that summarises and orders the previous discussion, as presented in Figure 1. The model incorporates the three operational approaches to demolition onsite where each carries different outcomes for timber recovery. Here, the deconstruction approach was found to provide high timber recovery but is mainly used where high-value timber waste was involved; the miscellaneous salvage approach provided some recovery of high and lowvalue timber; the crunch and dump approach provided low or no recovery, and was used where low and no-value timbers were involved. Unfortunately, there is a reverse order in terms of onsite productivity and as result, the crunch and dump approach is often used where timber waste is perceived to be of low value. Demolishers prefer what they perceive to be the cheapest and fastest option.

\section{Conclusions}

A process driven decision model for demolition and waste recovery has been developed. In making use of the model for the specific purposes of timber recovery, a number of conclusions can be made, each carrying implicit recommendations for future actions, as discussed below. In terms of the Initiators of demolition and the potential waste created, it is concluded that there will gradually be a depleting supply of sawn hardwood waste and an increasing supply of sawn softwood and engineered timber waste. Timber recovery and recycling strategies need to adapt to suit this future supply.

Market value is the single biggest Organisational Driver impacting on timber waste recovery. Timber waste can vary widely in value and there needs to be an industry re-think about how to generate more value out of softwood and engineered timber waste to make them more worthwhile to recover and making timber more prominent in terms of the demolition processes selected. 


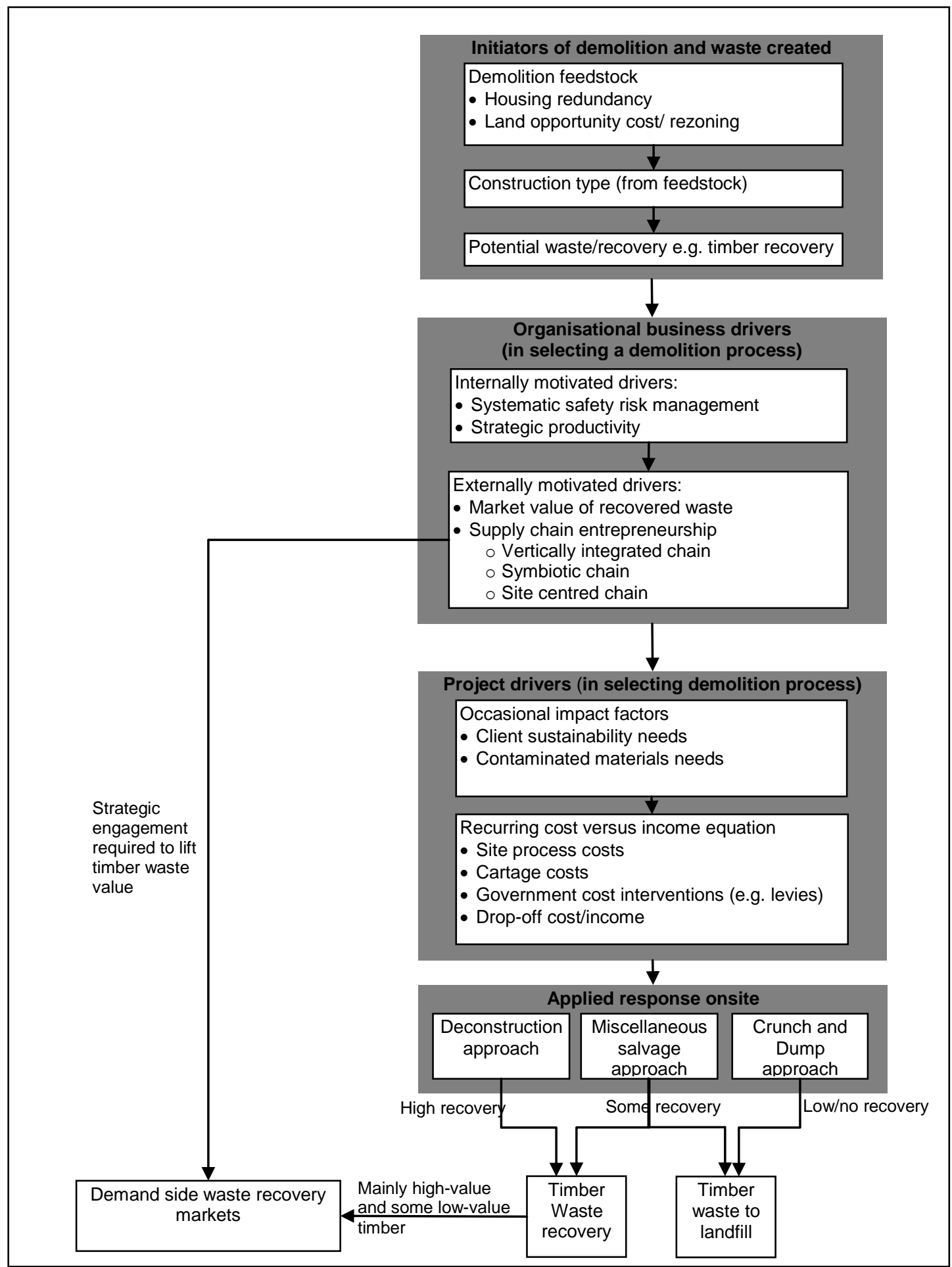

Figure 1: Process model of demolition decision making and timber waste recovery

Site safety requirements may limit the viability of the deconstruction approach to demolition because of its exposure to safety risk. Since this approach provides the best recovery of timber it is worth considering ways of improving and retaining its longer term viability.

Consistent with the previous point, there is considerable potential to extend usage of the miscellaneous salvage approach by developing excavator driven attachments to assist in 
separating and recovering framing timber via advanced grabbing attachments, sawing attachments and bucket based sieve attachments.

Fragmentation and low economies of scale are likely to cause trends towards lumping different categories of timber waste together for low value uses such as bio-fuel, landscaping mulch and particleboard manufacture. This suits the crunch and dump approach and may offer a viable short to mid-term solution for low-value timber recovery but is reliant on increased development of offsite mechanised processing facilities capable of extracting timber from mixed waste. The main disadvantage of this approach is that it brings all timber down to the lowest common denominator, thus achieving the lowest rather than highest value return on the timber. A mid to long term industry goal should be to work towards retaining higher value.

There is a need to re-think and evolve supply chains to more efficiently cater for timber waste of different value - especially the increasing supply of no-value and low-value waste timber. This could be assisted by developing a standard means for grading, qualifying and quantifying timber waste to assist categorised trading of recovered timber and to facilitate the highest value use of recovered timber. There is also the need for improvements in collection and aggregation points for low-value timber waste to improve economies of scale and reduce cartage costs. Further, there is a latent ability to increase the efficiency of site centred supply chains - by focusing on quick transactions using web based e-commerce.

While the above points tend to focus on short to mid term considerations, there is also scope to consider longer term needs to rethink the design of buildings for greater reuse and deconstructability of buildings. This could be developed in conjunction with other moves towards standardised and industrialised methods of construction with the aim to provide greater re-use of timber components, greater safety in dismantling construction and the potential to attain higher value from recovered timber components. Such a move would also be consistent with sustainable building practise.

The scope of the model developed here is limited by the context of the research method and its application to housing demolition, but is presented in a way that makes it testable and usable beyond these limits including application to other building types and building materials. With this in mind, future research may confirm the validity of the model across a broader range of demolition projects and use it as a tool for understanding and diagnosing impediments to the recovery of different materials.

\section{References}

Australian Greenhouse Office (2004) Waste Sector - Greenhouse Gas Emissions Projections 2004, Commonwealth of Australia

Alexander, J. (1993) 'Making job site recycling work', Journal of Light Construction, 12 (2), 28-29

Begum, R. A., et al. (2006) 'A benefit-cost analysis on the economic feasibility of construction waste minimisation: The case of Malaysia', Resources, Conservation and Recycling, 48, 86-98

Boyatzis, R. E. (1998) Transforming qualitative information - Thematic analysis and code development, London, Sage Publications

Dainty, A. R. J. and R. J. Brooke (2004) 'Towards improved construction waste minimisation: A need for improved supply chain integration', Structural Survey, 22 (1), 20-29

Duran, X., et al. (2006) 'A model for assessing the economic viability of construction and demolition waste recycling - the case of Ireland', Resources, Conservation and Recycling, 46, 302-320 
Falk, R. (1997) 'Wood Recycling: Opportunities for wood waste resource', Forest Products Journal, 47 (6), 17-22

Gomes, C. F. S., et al. (2008) 'Multicriteria decision making applied to waste recycling in Brazil', Omega, 36 (3), 395-404

Gray, R. (2002) 'Antipollution Options Considered on Construction Sites', Water Engineering \& Management 149 (7), 5.

Helper, H. (1994) 'C \& D wasterecycling: razing consciousness', American City and Country, 109 (1), 32-42

Hendriks, C., et al. (2000) 'Material flow analysis: a tool to support environmental policy decision making', Local Environment, 5 (3), 311 - 328

Hurley, J. W., et al. (2001) Deconstruction and reuse of construction materials, Watford, Building Research Establishment

Infield (2007) Review of International EPR schemes \& timber recycling, Sydney, Infield

Kalin, Z. (1991) 'Canada targets C \& D debris', Biocycle, 32 (1), 35-36

Kartam, N., et al. (2004) 'Environmental management of construction and demolition waste in Kuwait', Waste Management, 24 (10), 1049-1059

Klang, P., et al. (2003) 'Sustainable management of demolition waste - an integrated model for the evaluation of environmental, economic and social aspects', Resources, Conservation and Recycling, 38 (4), 317-334

Krook, J., et al. (2007) 'Swedish recovered wood waste: Linking regulation and contamination', Waste Management, 28, 638-648

Lélé, S. M. (1991) 'Sustainable development: A critical review', World Development 19 (6), 607-621

Lu, M., et al. (2006) 'Application Framework for Mapping and Simulation of Waste Handling Process in Construction', Journal of Construction Engineering \& Management, 132 (11), 1212-1221

Magin, G. (2001) An introduction to wood waste in the UK, Fauna \& Flora International, Cambridge, UK, 40

McDonald, B. and Smithers, M. (1998) 'Implementing a waste management plan during the construction phase of a project: a case study', Construction Management and Economics, 16 (1), 71 - 78

Mills, T. H. and Showalter, E. (1999) 'A Cost-Effective Waste Management Plan', Cost Engineering, 41 (3), 35

Mills, T. H. and Showalter, E. (2001) 'A Cost-Effective Waste Management Plan', Cost Engineering 41 (3): 35

Moriguchi, Y. (1999) 'Recycling and waste management from the viewpoint of material flow accounting', J Mater Cycles Waste Manag, 1, 2-9

Morris, J. R., et al. (2002) 'The UK landfill tax: Financial implications for local authorities', Public Money and Management, 20 (3), 51-54

Muller, D. B. (2006) 'Stock dynamics for forecasting materials flow - Case study for housing in The Netherlands', Ecological Economics, 59, 142-156

Nabil Kartam, et al. (2004) 'Environmental management of construction and demolition waste in Kuwait', Waste Management, 24, 1049-1059

Poon, C. S. (1997) 'Management and recycling of demolition waste in Hong Kong', Waste Management \& Research, 15 (6), 561-572 
Poon, C. S., et al. (2004) 'Reducing building waste at construction sites in Hong Kong', Construction Management \& Economics, 22 (5), 461-470

Poon, C. S., et al. (2001) 'On-site sorting of construction and demolition waste in Hong Kong', Resources Conservation \& Recycling, 32, 157-172

Pun, S. K., et al. (2006) 'Case study of demolition costs of residential buildings, Construction Management and Economics, 24, 967-976

Rodríguez, G., et al. (2007) 'The contribution of environmental management systems to the management of construction and demolition waste: The case of the autonomous community of Madrid (Spain)', Resources, Conservation and Recycling, 50 (3), 334-349

Schachermayer, E., et al. (2000) 'Assessment of two different separation techniques for building waste', Waste Management \& Research, 18 (1), 16-24

Shen, L. Y., et al. (2004) 'Mapping Approach for Examining Waste Management on Construction Sites', Journal of Construction Engineering \& Management, 130 (4), 472-481

Shibata, T., et al. (2006) 'Arsenic Leaching from Mulch Made from Recycled Construction and Demolition Wood and Impacts of Iron-Oxide Colorants, Environmental Science \& Technology, 40 (16), 5102-5107

Skumatz, L. A. (1993) Variable rates for municipal solid waste: implementation, experience, economics and legislation, Los Angeles, Reason Foundation

Skumatz, L. A. (2008) 'Pay as you throw in teh U.S.: Implementations, impacts, and experience', Waste Management 28 (12), 2778-2785

Smith, E. D. and Bishop, B. S. (2005) 'Benefits to groundwater quality by diverting construction and demolition wastes from landfills', International Journal of Environmental Technology \& Management, 5 (2/3), 1-1

Solo-Gabriele, H. and Townsend, T. (1999) 'Disposal practices and management alternatives for CCA-treated wood waste', Waste Management \& Research, 17, 378-389

Standing Committee on Environment Communications and the Arts (2008) Management of Australia's Waste Streams, Canberra, Senate of Australia

Suttie, E. (2004) Wood waste management - UK update. Lisbon, Portugal, BRE, Centre for Timber Technology \& Construction, 10

Tam, V. W. Y. and Tam, C. M. (2006) 'A review on the viable technology for construction waste recycling', Resources, Conservation and Recycling, 47, 209-221

Tanaka, K., et al. (2004) Development of New Recycle System of Used Lumber from Dismantled Wooden House, 8th World Conference on Timber Engineering, Finland

Treloar, G. J., et al. (2003) 'An analysis of factors influencing waste minimisation and use of recycled materials for the construction of residential buildings', Management of Environmental Quality: An International Journal, 14 (1), 134-145

World Commission on Environment and Development (1987) Our Common Future, Bruntland Report G. H. Brundtland. London, UK, World Commission on Environment and Development, General Assembly Resolution 42/187, 397

Xing, W. and C. Hendriks (2006) 'Decontamination of granular wastes by mining separation techniques', Journal of Cleaner Production, 14 (8), 748-753

Yin, R. K. (2008), Case Study Research: Design and Methods, Thousand Oaks, California, Sage Publications 